\section{Comment}

When prescribing drugs for use outside their licence, most specialists in palliative medicine do not routinely obtain verbal or written informed consent, document the reason for unlicensed use in the patient's notes, or inform other involved professionals of unlicensed use. When they do obtain consent, it is likely to be for the use of less established drugs and to be verbal rather than written. Strict adherence to the recommendations is not welcomed by palliative care specialists because of the number of drugs involved and the burden to patients and carers.

This view is shared by the Royal College of Paediatrics and Child Health-the use of drugs outside their licence is also common in paediatrics-which has stated that in general it is not necessary to obtain the explicit consent of parents, carers, or patients for un- licensed use. The royal college has also stated that NHS trusts and health authorities should support therapeutic practices that are advocated by a respectable, responsible body of professionals. ${ }^{45}$

Contributors: AW conceived the survey. HP and AW collated and analysed the data and wrote the paper, and both will act as guarantors.

Competing interests: None declared.

Atkinson CV, Kirkham SR. Unlicensed uses for medication in a palliative care unit. Palliat Med 1999;13:145-52.

2 Todd J, Davies A. Use of unlicensed medication in palliative medicine Palliat Med 1999;13:446.

3 Cohen PJ. Off-label use of prescription drugs: legal, clinical and policy considerations. Eur J Anaesthesiol 1997;14:231-5.

4 Royal College of Paediatrics and Child Health. Medicines for children. London: RCPCH, 1999.

5 Conroy S, Choonara I, Impicciatore P, Mohn A, Arnell H, Rane A, et al Survey of unlicensed and off label drug use in paediatric wards in European countries. BMJ 2000;320:79-82.

(Accepted 14 May 2001)

\title{
Adverse events following acupuncture: prospective survey of 32000 consultations with doctors and physiotherapists
}

\author{
Adrian White, Simon Hayhoe, Anna Hart, Edzard Ernst
}

Acupuncture is increasingly popular, but it is not free from risk for the patient. ${ }^{1}$ Safety is best established with prospective surveys. Our aim was to ascertain the incidence of adverse events related to acupuncture treatment, as currently practised in Britain by doctors and physiotherapists.

\section{Participants, methods, and results}

Volunteer acupuncture practitioners were recruited through journals circulated to members of the British Medical Acupuncture Society and the Acupuncture Association of Chartered Physiotherapists (approximately 2750 members). ${ }^{2}$ A prospective survey was undertaken using forms for intensive event monitoring that had been piloted previously. ${ }^{3}$ Minor adverse events were defined as "any ill-effect, no matter how small, that is unintended and non-therapeutic, even if not unexpected." These events were reported every month, along with the total number of consultations. Minor or serious events that were considered to be "significant"-"unusual, novel, dangerous, significantly inconvenient, or requiring further information"-were reported on separate forms when they occurred. Anonymous reporting was accepted. A sample size of 30000 consultations was necessary to identify with $95 \%$ confidence any adverse event with a frequency of 1 in 10000 consultations. $^{4}$

Estimates of incidences per 10000 population were calculated with the acupuncturist (not the consultation) as the primary sampling unit. Since the data were skewed, with extreme values present, confidence intervals corrected for bias were calculated using bootstrapping procedure "bs" on estimates from the function "svyratio" in intercooled Stata version 6.0 with 10000 replications.
Data were collected from June 1998 to February 2000 from 78 acupuncturists, 13 of whom chose to remain anonymous. The average age of the acupuncturists was 47 (range 27-71) years, 61\% were doctors and $39 \%$ physiotherapists, and $71 \%$ had practised for five years or more. In all, 31822 (median 318, range 5-1911) consultations were included.

Altogether, 43 "significant" events were reported (table), giving a rate of 14 per 10000 (95\% confidence interval 8/10 000 to 20/10 000). In addition, 48 apparently similar events were reported on the monthly forms, presumably due to different interpretations of "significant". All adverse events had cleared within one week, except for one incident of pain that lasted two weeks and one of sensory symptoms that lasted several weeks. According to accepted criteria, ${ }^{3}$ none $(0 / 10000$ to $1.2 / 10000)$ of these events was serious.

A total of 2135 minor events was reported, giving an incidence of 671 per $10000(42 / 10000$ to $1013 /$ $10000)$ consultations. The most common events were bleeding (310 (160 to 590) per 10000 consultations) and needling pain (110 (49-247) per 10000 consultations). Aggravation of symptoms occurred in 96 (43-178) per 10000 consultations; in 70\% of these cases, there was a subsequent improvement in the presenting complaint. The highest rates reported by individual acupuncturists, expressed as a percentage of consultations, were 53\% for bleeding, 24\% for pain, and $11 \%$ for aggravation of symptoms.

\section{Comment}

Doctors and physiotherapists who performed acupuncture reported no serious adverse events and 671 minor adverse events per 10000 acupuncture consultations. These rates are classified as minimal ${ }^{5}$; however, 14 per 10000 of these minor events were reported as
University of Nottingham and Hayward House Macmillan Specialist Palliative Care Unit

Andrew Wilcock senior lecturer in palliative medicine and medical oncology Correspondence to: A Wilcock andrew.wilcock@ nottingham.ac.uk

See Editorial by Vincent and p 486

Department of Complementary Medicine, School of Postgraduate Medicine and Health Sciences, University of Exeter EX2 4NT

Adrian White senior lecturer Edzard Ernst professor Pain Clinic, Colchester District General Hospital,

Colchester CO4 5JL

Simon Hayhoe anaesthetist Faculty of Science, University of Central Lancashire, Preston PR1 2HE

Anna Hart principal lecturer Correspondence to: A White

a.r.white@ex.ac.uk

BMJ 2001;323:485-6 
Significant minor events reported by 78 doctors and physiotherapists in 31822 acupuncture consultations

Event

Administration problems:

Needle lost or forgotten

Patient forgotten in treatment room 2

Application site problems:

Cellulitis after treatment of oedematous leg ${ }^{\star}$

Blister following moxibustion

\begin{tabular}{ll} 
Needle allergy & 2 \\
\hline Needle site pain* (one case lasted 2 weeks) & 3
\end{tabular}

Cardiovascular problems:

Fainting 6

Gastrointestinal problems:

Nauseat 2

Vomiting

General problems:

Patient fell asleep during treatment

Drowsiness ${ }^{*}$ (one case lasted 1 day; one case lasted 1 week

Disorientation (one case lasted 1 hour; one case lasted 1 day)

Lethargy*

Neurological and psychiatric problems:

Anxiety and panic† (one episode lasted 60 hours) 2

Euphoria

Headache for 3 days

Hyperaesthesiae with numbness for 3 days $^{\star}$

Seizure shortly after insertion of needles (probably reflex anoxic) ${ }^{\star}$

Slurred speech

Exacerbation of symptoms:

Back pain, fibromyalgia, ${ }^{*}$ shoulder pain, ${ }^{*}$ vomiting, ${ }^{*}$ migraine ${ }^{\star}$

*Event led to reduction in daily activities in one patient.

tEvent led to reduction in daily activities in two patients.

significant. These event rates are per consultation, and they do not give the risk per individual patient.

Demographic data suggest that the acupuncturist volunteers were reasonably representative of the mem- bers of the two societies, but over-reporting and underreporting are inherently possible in such studies. High individual rates may be due to a low personal threshold for reporting, or they may indicate the need for further training of the acupuncturist. Some avoidable adverse events occurred, and acupuncturists might consider modifying their practice to reduce the incidence of such events.

We thank members of the British Medical Acupuncture Society and the Acupuncture Association of Chartered Physiotherapists for collecting data, Mike Fitter and Hugh MacPherson for advice in designing the questionnaire, and Val Hopwood for help in recruiting volunteers.

Contributors: EE, SH, and AW planned the study, which was supervised by AW. The data were collected by members of the British Medical Acupuncture Society and the Acupuncture Association of Chartered Physiotherapists. The results were collated by $\mathrm{AW}$, and $\mathrm{AH}$ performed the statistical analysis. The final report was written by $\mathrm{AW}, \mathrm{SH}, \mathrm{AH}$, and EE. AW and EE will act as guarantors.

Funding: The posts of $\mathrm{AW}$ and $\mathrm{EE}$ are funded by the Maurice Laing Foundation.

Competing interests: AW has received fees for lecturing at scientific and educational meetings arranged by the British Medical Acupuncture Society and the Acupuncture Association of Chartered Physiotherapists. SH has received fees for lecturing and for acting as editor of the professional journal of the British Medical Acupuncture Society, Acupuncture in Medicine.

1 Ernst E, White A. Life-threatening adverse reactions after acupuncture? A systematic review. Pain 1997;71:123-6.

2 White AR, Hayhoe S, Ernst E. Survey of adverse events following acupuncture. Acupunct Med 1997;15:67-70.

3 Edwards RI, Aronson JK. Adverse drug reactions: definitions, diagnosis, and management. Lancet 2000;356:1255-9.

4 Eypasch E, Lefering R, Kum CK, Troidl H. Probability of adverse events that have not yet occurred: a statistical reminder. BMJ 1995;311:619-20.

5 British Medical Association Ethics. Medical ethics today. Its practice and philosophy. London: BMA Professional Division Publications, 1993

(Accepted 17 May 2001)

\title{
The York acupuncture safety study: prospective survey of 34000 treatments by traditional acupuncturists
}

\author{
Hugh MacPherson, Kate Thomas, Stephen Walters, Mike Fitter
}

See Editorial by

Vincent and $\mathrm{p} 485$

Foundation for Traditional Chinese Medicine, York YO24 4EY

Hugh MacPherson research director

Mike Fitter

research consultant

continued over

BMJ 2001;323:486-7
Recent reports have highlighted the importance of having good evidence on the safety of acupuncture. ${ }^{12}$ Sound evidence on the risks associated with acupuncture is, however, scarce. ${ }^{3}$ Our primary aim, therefore, was to describe the type and frequency of adverse events after acupuncture. A secondary aim was to examine mild transient reactions associated with acupuncture, some of which may indicate a positive response to treatment.

\section{Participants, methods, and results}

The study involved a prospective postal audit of treatments undertaken during a four week period in 2000. All 1848 professional acupuncturists who were members of the British Acupuncture Council and were practising in the United Kingdom were invited to record details of adverse events and mild transient reactions after treatment. Standardised self report forms were used. Participating practitioners also provided information on themselves, including age, sex, length of training, and years of practice. To have a $95 \%$ probability that no serious event occurs in $n$ treatments, a survey sample size needs to be three times $n{ }^{4}$ On this basis, a sample of 30000 treatments was sought. Piloting indicated that a four week period was needed.

A total of 574 practitioners participated, $31 \%$ of the total population. The mean age of participants was 44.8 years (range $23-79$ years), $65 \%$ were female, and $62 \%$ had been practising acupuncture for more than five years. Information on sex, training college, and length of practice was available from the British Acupuncture Council's database. Participants were sufficiently representative of the population of practitioners for a re-weighting of the primary data to be unnecessary. Participating practitioners reported on 34407 treatments. 